\title{
A proposal to use plant demographic data to assess potential weed biological control agents impacts on non-target plant populations
}

\author{
Bernd Blossey $\cdot$ Andrea Dávalos $\cdot$ Wade Simmons $\cdot$ Jianqing Ding
}

Received: 14 November 2017 / Accepted: 25 April 2018/Published online: 28 April 2018

(C) The Author(s) 2018

\begin{abstract}
Weed biocontrol programs aim to reduce the spread and population growth rate of the target plant while stabilizing or increasing populations of those native species considered under threat by invasive plants. This goal is not unique to weed biocontrol but applies to all other invasive plant management techniques, though such information is rarely collected. Without this information, success of management interventions can be ambiguous, and regulatory agencies, the public, policy makers, funders and land managers cannot be held accountable for chosen treatments. A fundamental reform, including use of demographic studies and long-term
\end{abstract}

Handling Editors: Mark Schwarzländer, Cliff Moran and S. Raghu.

Electronic supplementary material The online version of this article (https://doi.org/10.1007/s10526-018-9886-4) contains supplementary material, which is available to authorized users.

B. Blossey $(\square) \cdot$ W. Simmons

Department of Natural Resources, Cornell University,

Ithaca, NY 14853, USA

e-mail: bb22@cornell.edu

\section{A. Dávalos}

Biological Sciences, SUNY Cortland, 1215 Bowers Hall, Cortland, NY 13045, USA

\section{J. Ding}

College of Life Sciences, Henan University,

Kaifeng 475004, Henan, China assessments, are essential to guide weed biocontrol programs. We propose to add use of plant demography (an assessment of how environmental factors and ecological interactions, for example competition, disease or herbivory, may affect plant populations by altering survival, growth, development and reproductive rates of plant individuals) during host specificity risk assessments of potential biological control agents. Demographic models can refine assessments of potential impacts for those plant species that experience some feeding or larval development during host specificity testing. Our proposed approach to focus on impact on plant demography instead of attack on plant individuals is useful in appropriately gauging threats potential weed biocontrol agents may pose to non-target species after field release.

Keywords Demography $\cdot$ Host specificity $\cdot$ Non target effects - Risk assessment - Trapa natans L. . Weed biocontrol

\section{Introduction}

Biological weed control programs aim to find organisms able to reduce spread and population growth rate of target plants, while avoiding non-target impacts. The track record of weed biocontrol over the past century is decidedly mixed, since only a third of all weed biocontrol programs achieve at least partial 
suppression of targets (Crawley 1989; Fowler et al. 2000; Moran et al. 2005). Many biocontrol agents fail to establish, or fail to control host plants (Crawley 1989; McFadyen 1998). On the other hand, while occasionally contested, the safety record of weed biocontrol is superior to other management methods, while economic and ecological benefits can be enormous and continue to accrue (Moran et al. 2005; Suckling and Sforza 2014).

Following publications of high profile cases of nontarget attack by Rhinocyllus conicus Frölich (Curculionidae) and Cactoblastis cactorum Berg (Pyralidae), respectively, changes in decision making processes in regulatory agencies, particularly in the USA, shifted to a greater reliance on fundamental host-range data, a change that further threatens release even of highly specific agents (Hinz et al. 2014). The irony of this change in risk perception is that specific and successful agents of the past would have difficulties passing through current approval processes (Groenteman et al. 2011; Hinz et al. 2014). At a time when it is becoming increasingly evident that many invasive species control methods, particularly chemical management, are unable to achieve lasting control and may in fact threaten non-target species (Kettenring and Adams 2011; Pearson et al. 2016), we argue that it is time for fundamental reform of risk assessment and decision making processes in invasive plant management and weed biocontrol that is guided by appropriate scientific information and open dialogue, not fear (Blossey 2016b).

We propose that adoption of modern scientific tools focusing on demographic impacts of herbivores could constitute a breakthrough development in maintaining safety while increasing the ability to select effective herbivores. We consider it paramount to shift nontarget risk assessments away from damage to individuals to population level effects expected after field releases. We envision that traditional reductionist approaches (no-choice, small herbivore confinements, followed by multiple-choice or potted plant experiments) will continue to be the mainstay of host specificity testing. These tests are valuable because the vast majority of test plant species will not be attacked even under constrained conditions (Fig. 1). However, in many programs often a few test plant species remain that may be fed upon, are accepted for oviposition, or even allow larval development (albeit at a greatly reduced rate compared to original host plants) by

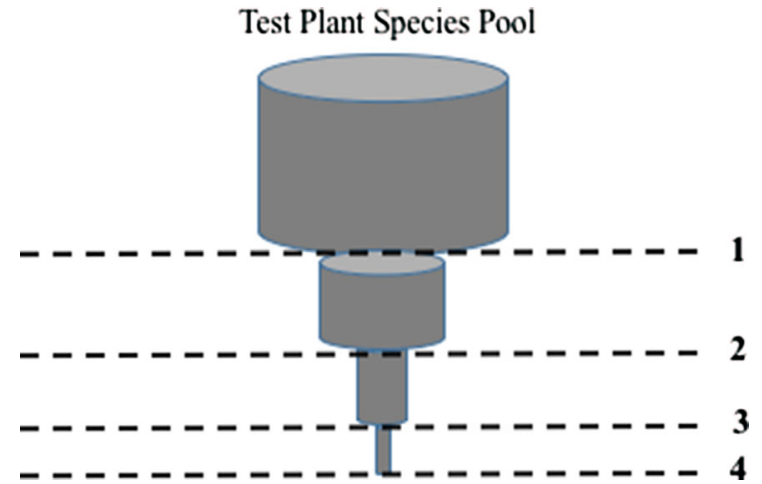

Fig. 1 Schematic design of typical proposed host specificity testing protocol for potential weed biocontrol agents. Depending on life history and feeding mode of the herbivore under consideration, test conditions may vary. Pool 1 includes all plant species proposed for host specificity testing that are tested using highly constrained no-choice conditions (Screen 1). Those species that could not be eliminated in the first screening step constitute pool 2 which are tested using more sophisticated designs, such as multiple-choice tests using potted plants or larger cages (screen 2). Species in pool 3 include plant species that were still attacked under the more sophisticated test conditions, or where larvae completed development. Tests utilized during screen 3 depend on herbivore feeding niches and logistical and regulatory considerations but include use of common gardens, multiple choice tests without containment, etc. Only those species that were still attacked under the most realistic conditions possible in a particular program would then be considered candidate species for demographic analyses (screen 4). Note that the pool of species shrinks with each test, while the realism of testing conditions and their ecological relevance increases

highly specific herbivores. We propose to utilize plant demography (an assessment of how environmental factors and ecological interactions, for example competition, disease or herbivory, may affect plant populations by altering survival, growth, development and reproductive rates of plant individuals) (SalgueroGomez et al. 2015) to assess potential threats of candidate biocontrol agents to non-target species. This approach aims to provide a means by which to evaluate potential impacts to non-target plant populations. Our proposal constitutes a significant shift in the way weed biocontrol researchers, review panels and others may look at the approval and risk assessment process-but it is a scientifically valid and biologically meaningful one. We are not concerned by host use but by negative impacts to populations of nontarget species. This is not a reduction in protections afforded to native species as it continues to safeguard all native species or valuable introduced species that 
have attained cultural, ornamental or agricultural significance. We argue that to "safeguard" means that populations of non-target organisms are maintained and do not suffer demographic declines due to biocontrol agent introductions. Cosmetic damage or even substantial damage to, or death of, individuals does not necessarily indicate demographic or ecological consequences.

The shift we propose will find resistance based on risk perceptions regarding safety of non-target plants due to concerns that herbivores introduced to control introduced plants will (1) attack (rare) native species leading to declines in populations of these species; and (2) that diet restriction (i.e. specificity) of weed biocontrol agents are "fluid" and change over time, leading to attack and unintended negative consequences for native species. We will briefly review evidence for these concerns before further developing our proposal to use demography in host specificity risk assessments. However, we first provide a primer on terminology used to describe plant-herbivore interactions because we believe that some differences in perceived risk perception are semantic.

\section{Terminology used in describing plant-herbivore interactions and weed biocontrol programs}

Ecologists typically refer to diets of herbivores using terms like specialists or generalists (Smilanich et al. 2016) or more specifically monophagous (feeding on a single or few species within a genus), oligophagous (utilizing several plant species, typically in different genera), and polyphagous (using different plant species in different genera and families) (Bernays and Chapman 1994). In contrast, weed biocontrol researchers typically focus on herbivores using a single plant species. Furthermore, "use" in the ecological and evolutionary literature typically refers to plants chosen for oviposition and allowing larval development in the field, recognized as realized host range in weed biocontrol. Experimental host-specificity testing aims to (1) elucidate the fundamental host range (plant species acceptable for feeding, oviposition and larval development using no-choice tests in the absence of the original host), and (2) provide additional data using less constrained and increasingly ecologically realistic testing procedures to allow forecasting of realized host ranges. Realized field host ranges are always narrower than experimentally determined fundamental host ranges.

\section{Evidence for threats of weed biocontrol agents to (rare) native plant species}

Reports of weed biocontrol agents attacking nontarget species do exist, including spillover events with substantial temporary defoliation of non-target species (Blossey et al. 2001; Louda et al. 1997, 2003; Paynter et al. 2008; Pemberton 2000; Suckling and Sforza 2014). Comprehensive reviews assessing weed biocontrol outcomes (Blossey et al. 2001; Suckling and Sforza 2014), conclude that $>90 \%$ of all biocontrol agents never attack non-target species. The majority of non-target feeding is attributed to spillover events and Suckling and Sforza (2014) report such attacks on 128 non-target plants. Host specificity testing appears unable to predict identity of these species, but physical proximity may explain some of it (Blossey et al. 2001).

However, occasional or prolonged host use appears highly predictable using fundamental host range data (Paynter et al. 2015). Fewer than ten biocontrol agents have established populations on non-target species, a risk that was known, and accepted by regulatory agencies, at time of their introduction (Blossey et al. 2001). Of these, only three, $R$. conicus, $C$. cactorum and Trichosirocalus horridus (Panzer) (Curculionidae) may have effects that reduce populations and growth rates of non-target species (Louda et al. 1997; Suckling and Sforza 2014; Takahashi et al. 2009). None of these herbivores would be approved under current decision making frameworks (McFadyen 1998; Suckling and Sforza 2014).

Detailed documentation of non-target plant species occasionally attacked by biocontrol agents offer assurances that significant non-target effects have not gone unrecognized or unreported-in this case absence of evidence indicates evidence of absence of such effects and not just lack of effort. A recent literature survey of threats by insect herbivores to rare plants concluded that with exception of $R$. conicus and C. cactorum, "currently this threat is either seldom realized (perhaps because of extensive pre-release screening in modern biocontrol programs) or else seldom documented" (Ancheta and Heard 2011). 


\section{Lack of evidence for evolution of dietary preferences in weed biocontrol agents}

Permitting processes for biocontrol agent releases may differ widely among countries (Sheppard and Warner 2016), but host specificity tests are widely standardized (Wapshere 1974). Despite further refinements proposed and implemented in subsequent years (Briese 2005; Clement and Cristofaro 1995; Sheppard et al. 2005; USDA 2016), this sequence of testing has largely remained state-of-the-art, providing overwhelmingly safe weed biocontrol agents. There is no evidence that fundamental host ranges of biocontrol agents have evolved (Arnett and Louda 2002; Marohasy 1996; Paynter et al. 2004; Sheppard et al. 2005; van Klinken and Edwards 2002), despite dire warnings (Simberloff and Stiling 1996). There is, however, evidence for evolution of improved performance on non-target plants (McEvoy et al. 2012) and we acknowledge that few formal assessments have been made.

However, occasional use, even if predicted, of species that are not targets of weed biocontrol, and frequent citation of the few species with anticipated large negative impacts, appears to be registered by non-biocontrol scientists as evidence for a poor track record and evolutionary malleable diet breadth of insect herbivores used in weed biocontrol. We argue that the problem arises due to the disconnect between perception of labile or rapidly evolving host ranges in weed biocontrol agents and available evidence. Weed biocontrol researchers have increased efforts to improve testing procedures to mitigate constraints of laboratory conditions that affect insect behavior to improve predictions of realized host ranges (Clement and Cristofaro 1995; Fowler et al. 2012; van Klinken and Edwards 2002). While such improvements are essential to increase reliability of predictions regarding realized host ranges, the focus on improving testing conditions appears to have prevented a discussion among scientists and regulatory agencies regarding the appropriate meaning of safeguarding other species (Hinz et al. 2014).

Clearly, diets of insect herbivores change over time and both generalists and specialists may acquire new hosts (Futuyma and Agrawal 2009). Range expansions through human aided introduction of novel plants or insects provide enormous ecological and evolutionary opportunities for herbivores to adopt new hosts.
Species accumulation curves on novel host plants plateau in approximately 100 years for generalists and 500-10,000 years for specialists (Bernays and Graham 1988). However, the vast majority of phytophagous insects show "phylogenetic conservatism" retaining their association with plant taxa over millions of years with $<10 \%$ of speciation events including a shift to a different plant family (Winkler and Mitter 2008). Biocontrol agents passing through host range testing, as far as we can tell from decades of observation and study, appear particularly "conservative".

We now return to our argument that use of demographic models should be a desired and required tool during risk assessment of biocontrol agents. We are not the first to propose such new tools (Louda et al. 2005a; Raghu et al. 2006; Sauby et al. 2017), although we believe we are the first to ask that this becomes part of pre-release risk assessments. We will briefly introduce concepts of demographic modeling and then provide examples how demography has, and can be utilized in weed biocontrol. To the best of our knowledge, no biocontrol program has used demographic information to assess risks to non-targets before field releases, so we will rely on post-release analyses and a hypothetical scenario involving a current target of biocontrol research, water chestnut, Trapa natans L. (Lythraceae) to illustrate our proposal.

\section{Using demography to evaluate biocontrol agent risks to non-target plants}

Demography and matrix population models (Caswell 2001) are now common tools in biology (Caswell and Salguero-Gomez 2013) and their use in invasion biology and weed biocontrol is increasing (Carvalheiro et al. 2008; DeWalt 2006; Eckberg et al. 2014; Kerr et al. 2016; McEvoy and Coombs 1999; Shea and Kelly 1998; Swope et al. 2017). Technical background is provided elsewhere (Caswell 2001; Caswell et al. 2011; Caswell and Salguero-Gomez 2013; Williams et al. 2001), but briefly development of demographic models requires estimating vital rates, the transition probabilities from one life stage to another. For plants with clear developmental stages, a stage-based model requires estimation of transitions from seed, to seedling, to rosette to flowering plant, to seed output, 
back to seed and seed bank (Davis et al. 2006; Shea and Kelly 1998). Local abiotic conditions, competition, herbivores, stochasticity, density dependence and other processes may affect survival and the probability that an individual will transition from one stage to the next. Vital rates can be inferred in the field by monitoring cohorts of marked individuals.

Demographic models can aide in assessments of potential impacts of proposed biocontrol agents on non-target plants that could not be excluded using traditional testing sequences (Fig. 1). We propose use of experiments, for example by manipulating herbivore access or attack rates and then measuring stage specific reductions in survival, recruitment, growth, biomass, or seed output of non-target plants, which can be done in common gardens, or other confinements when insects are not approved for release. Constructing and populating models with data, and analyzing model performance under different scenarios (often referred to as perturbation analysis) allows comparisons of contributions made by different vital rates for overall population growth rates (Caswell 2000). The outcome of these exercises is the ability to forecast population growth rates $(\lambda)$, population fluctuation and potential extinction risk, and the sensitivity of growth rates to small changes in vital rate values, regardless of which management action is applied (Kerr et al. 2016). We recognize that demographic approaches during evaluation of potential biocontrol agents will have to contend with many different obstacles, the smallest among them may be lack of familiarity of biocontrol scientists with demographic modeling (Blossey 2016b). But this is a small price to pay for the ability to improve predictability of impacts to targets or risks to non-target organisms. Furthermore, a fast growing and increasingly utilized open access database, COMPADRE, provides a potentially important resource to inform construction of appropriate models for species of interest (Salguero-Gomez et al. 2015).

\section{Retrospective demographic analyses for target and non-target effects in weed biocontrol}

Demographic modeling has been used to understand success or failure of weed biocontrol programs in reducing target plant population growth rates (Buckley et al. 2004; DeWalt 2006; Shea and Kelly 1998;
Shea et al. 2005; Swope et al. 2017). These examples are important in recognizing that demographic approaches are already an important part of the evaluation process in weed biocontrol. We will not review these here but focus instead on efforts to help assess demographic impacts of weed biocontrol agents on non-target plants after release. Twenty years have passed since the initial widespread criticism regarding safety of (weed) biocontrol (Louda et al. 1997; Pemberton 2000; Simberloff and Stiling 1996). At least ten biocontrol agents have established populations on non-target species and $>120$ non-target plants are reported to be attacked (Blossey et al. 2001; Suckling and Sforza 2014), thus we expected to find numerous publications outlining demographic consequences, or at least attempts to evaluate consequences of such attacks. Our Web of Science searches uncovered few studies, which may indicate that they either were not conducted, did not get published, or were deemed unimportant to conduct or fund. We therefore focus on $R$. conicus and C. cactorum, species that according to categorization by Suckling and Sforza (2014) have "massive" non-target impacts, plus post-release evaluations of Mogulones crucifer Pallas (Curculionidae), a species approved for release against houndstongue (Cynoglossum officinale L.) (Boraginaceae) in Canada (Catton et al. 2016). Apparently, studies evaluating demographic effects of $T$. horridus beyond documentation of attack on a non-target plants do not exist, therefore we exclude this species.

A high-profile paper regarding non-target effects of $R$. conicus (Louda et al. 1997) tabulated attack rates on native thistles, but fell short of documenting demographic effects, which were strongly implied due to seed limitation and large demographic impacts by native seed feeders on Cirsium altissimum (L.) Spreng (Asteraceae) (Guretzky and Louda 1997). Additional investigations clearly documented demographic threats by $R$. conicus (Louda et al. 2005b) based both on field and laboratory data. But effects appear context-dependent and do not occur every year and in every location (Rand and Louda 2004; Rose et al. 2005). In addition, some native thistles show positive population growth rates even in the presence of and attack by $R$. conicus (DePrenger-Levin et al. 2010). Furthermore, results of demographic models to assess population growth rates for Platte thistle, Cirsium canescens Nutt. concluded that impacts may be 
substantial, but variable in space and time and not as catastrophic as previously feared (Rose et al. 2005). While $R$. conicus should have never been approved for release, current evidence is of widespread attack on native Cirsium species, but evidence for predicted massive negative demographic non-target effects (sensu Suckling and Sforza 2014) has not been presented at this time.

The accidental introduction of $C$. cactorum to North America (Pemberton 1995) raised concerns over safety of native North and Central American Opuntia spp. (Cactaceae) (Vigueras and Portillo 2001), particularly for rare endemics, such as Opuntia corallicola Small where only 12 known individuals existed in the Florida Keys (Johnson and Stiling 1996). Follow-up work, including using plant demography, over the past two decades has delivered a more refined view of realized threats. While initial introductions to Nevis and St. Kitts in the Lesser Antilles to control weedy native Opuntia spp. was ill advised, a survey 50 years after $C$. cactorum releases showed that the targeted native species Opuntia triacantha (Willd.) Sweet and Opuntia stricta (Haw.) Haw. remain under biological control while the native tree pear Consolea rubescens (Salm-Dyck ex DC) Lem. (Cactaceae) was not attacked and the cultivated and naturalized Opuntia cochenillifera (L.) Mill showed limited feeding by C. cactorum (Pemberton and Liu 2007). In the Southeastern USA, C. cactorum has spread rapidly, resulting in variable impacts depending on cactus species, often resulting in size decreases and reduction in relative growth rates (Sauby et al. 2017). Jezorek et al. (2012) summarized these findings as follows: "although C. cactorum should still be considered a threat, particularly for rare opuntioids, overall survival along the west central Florida coast is currently high and plants that are able to survive $C$. cactorum attack are not being reduced in size, possibly because they possess traits that render them more tolerant of $C$. cactorum damage. Our findings suggest that an assumption of severe negative effects of an invasive species, based on its effects in other regions or over short periods of time, may not always be justified". In the case of the rare endemic $O$. corallicola, detailed studies and restoration efforts revealed that salinity, moisture conditions, hurricanes, trampling by deer, and stem rot over the past two decades were more important demographic threats than C. cactorum (Stiling et al. 2000). Only by developing detailed models incorporating more than presence of herbivore attack and other "stressors" are we able to gauge impacts appropriately. As in the case of $R$. conicus, anticipated "massive" impacts of $C$. cactorum are, according to published studies, not currently materializing in the field.

Risk assessment after release of $M$. crucifer, a root feeding weevil that attacked some Boraginaceae, including some US native and rare plants, during host specificity testing (De Clerck-Floate and Schwarzländer 2002), provides a good example of an application of matrix population models. Canadian authorities granted release permits and $M$. crucifer established and began to spread in British Columbia, prompting fears about non-target attacks upon arrival in the USA (Andreas et al. 2008). Additional host specificity testing, including field tests in British Columbia, also documented non-target attack by $M$. crucifer but found minor adult feeding and infrequent larval development, despite ability of the weevil to complete development under no-choice conditions (De Clerck-Floate and Schwarzländer 2002).

Subsequent monitoring showed that M. crucifer did not establish at sites where $C$. officinale was absent (Catton et al. 2015) and attack of non-target species tapered off within a few meters (Catton et al. 2014), including during spillover events. Furthermore, detailed demographic work on Hackelia micrantha (Eastw.) J. L. Gentry (Boraginaceae), a native plant species regularly attacked in the field, demonstrated that while population growth rates for $C$. officinale were reduced below replacement rates $(\lambda<1), H$. micrantha benefitted from $C$. officinale reductions (Catton et al. 2016). These results indicate that while individual $H$. micrantha are being attacked and allow larval development of $M$. crucifer, the species is safe and suffers no harm at the population level (Catton et al. 2016). Similar demographic experiments with rare plants that are part of the fundamental host range of $M$. crucifer could help evaluate real (vs. feared) threats to other US native Boraginaceae.

These examples showcase the value of detailed demographic studies to assess how attack by biocontrol agents may, or may not, contribute to harm, or endangerment of non-target species. Only through such detailed work are we able to separate anecdotal observation of attack from contributions of many factors (habitat loss and fragmentation, inbreeding depression, succession, disturbance, climate, abiotic 
conditions, competition, other natural enemies, etc.) that affect plant demography simultaneously.

To the best of our knowledge, no biocontrol program has used a demographic analysis to assess herbivore impact on non-target plants pre-release or as part of a release petition. Raghu et al. (2006) proposed to use modeling a priori, but this recommendation followed rejection of a herbivore by Australian authorities due to minor feeding on a non-target plant. We believe weed biocontrol researcher should strive to make this standard practice when promising species fail traditional testing sequences (Fig. 1). Embracing this approach can lead to important collaborations with those concerned about native species and academics with specialized knowledge (Clewley et al. 2012).

To further develop our proposal to use plant demography models in pre-introduction risk assessments, we now turn to $T$. natans. We present data collection procedures used to develop a demographic model for T. natans. For the sake of argument, we assume $T$. natans to be a non-target species, and we further assume that two different chrysomelid beetles are potential biocontrol agents that failed to be cleared in traditional host specificity screening. We incorporate the feeding impacts of each herbivore into the demographic model to evaluate the risk each agent may pose to plant demography.

\section{Evaluation of two herbivores attacking $T$. natans}

The Eurasian T. natans is a floating aquatic annual plant invasive in North America where it is attacked by the native water lily leaf beetle, Galerucella nymphaeae L. while the extremely similar Galerucella birmanica Jacoby (Chrysomelidae) attacks T. natans in Asia (Ding and Blossey 2005; Ding et al. 2006a, b). Both herbivores are multivoltine and while $G$. nymphaeae is oligophagous with multiple host races (Cronin et al. 1999), G. birmanica is host-specific to $T$. natans, although it occasionally lays a few eggs on water shield, Brasenia schreberi J. Gmelin (Cabombaceae), the only other plant reported to be attacked in the field (Ding et al. 2006a) (natural histories of $T$. natans, B. schreberi, G. nymphaeae and G. birmanica are provided in Supplementary Materials, Section 1). Both herbivores were evaluated as potential biocontrol agents in experiments that assessed their impact on growth and reproduction of $T$. natans at different larval densities (0-50 $\mathrm{L}_{1}$ per rosette) (Ding and Blossey 2005; Ding et al. 2006b). We combine herbivore impact data with demographic plant data obtained in outdoor aquatic mesocosms to build demographic models that project future plant population dynamics under different beetle herbivory scenarios. These data were initially collected and the demographic model built to assess utility of each herbivore as a biocontrol agent. By considering, for sake of argument, T. natans as a non-target species, we can show how biocontrol programs can use demography in risk evaluation for non-target species. Full descriptions of the herbivore impact studies are available elsewhere (Ding and Blossey 2005; Ding et al. 2006b) and results and details of our experimental design to collect demographic data in aquatic mesocosms using four different plant populations collected in Massachusetts (MA), Rhode Island (RI), New York (NY), and Virginia (VA), USA are detailed in Supplementary Materials, Section 2.

Model development

We evaluated differences in population growth rate of T. natans with periodic matrix population models. Periodic matrix models are suited to explore within year transitions of annual organisms, such as T. natans (Caswell 2001). These models partition life history transitions into $m$ phases defined by a matrix $\left(\boldsymbol{B}_{h}\right)$ that projects the population into the next phase $(h$; where $h=1 \ldots m)$. Population over entire cycles is given by the product of period matrices: $\boldsymbol{A}=\boldsymbol{B}_{m} \boldsymbol{B}_{m-1} \ldots \boldsymbol{B}_{1}$; where $\boldsymbol{A}$ is the annual transition matrix. We partitioned T. natans life cycle into three phases (Fig. 2): fallspring (seedbank or new seeds germinate), springsummer (rosettes grow small or large), and summerfall (reproduction). We classified individuals in each life stage as seedbank, seeds, small or large plants and determined plant size as a function of surface area. We used census data from the common garden to estimate transition and germination rates and published data to calculate seedbank longevity (Kunii 1988) (Supplementary Materials, Table S3). We calculated annual population growth rate $(\lambda)$ given by the dominant eigenvalue of $\boldsymbol{A}$ and used bootstrap methods to estimate $95 \%$ confidence intervals for each population (defined as the 2.5 and $97.5 \%$ quantiles from a distribution based on resampling values with 


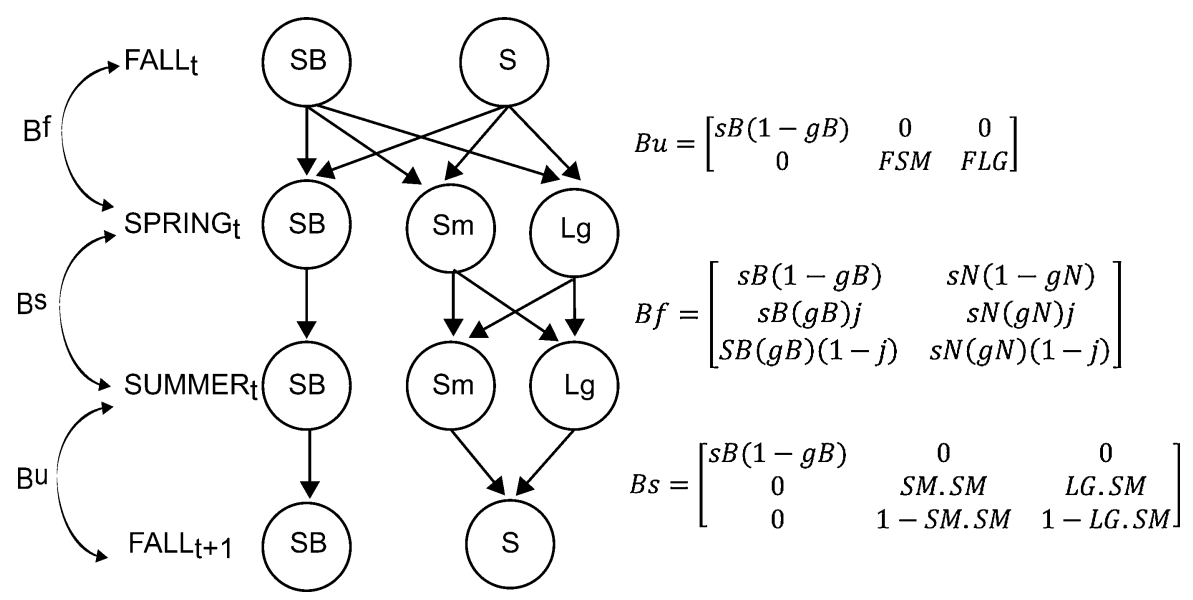

Fig. 2 Seasonal life cycle diagram and periodic matrices for $T$. natans. Each row represents a season and each circle a life stage (SB: seedbank, S: seed, Sm: small plant, Lg: large plant). Periodic matrix $\mathrm{Bf}$ represents germination of seeds from

replacement holding sample size constant for 1000 iterations) (Caswell 2001). We also conducted elasticity analyses on each periodic matrix to evaluate which transition most influenced growth rate (Caswell 2001; Smith et al. 2005).

\section{Non-target threat simulation}

We examined how presence and typical attack of $G$. nymphaeae or of $G$. birmanica affects demography of T. natans (Ding and Blossey 2005; Ding et al. 2006b). We modeled effects of each scenario on T. natans populations over ten time steps (t) and 10,000 iterations (i) and parametrized the model with values estimated from the common garden and the literature (Supplementary Materials, Table S3). We modeled stochastic variation following a two-step procedure in order to incorporate temporal variation and parametric uncertainty in model predictions (McGowan et al. 2011). We modeled temporal variation in survival rates and transition terms for each realization $i$ and time step $t$ as a beta distributed random variable with parameters $\alpha_{i}$ and $\beta_{i}$ derived from the mean survival (or transition) rate, $\mu_{\mathrm{i}}$, such that $\mu_{\mathrm{i}}=\alpha_{\mathrm{i}} /\left(\alpha_{\mathrm{i}}+\beta_{\mathrm{i}}\right)$ and $\sigma_{\mathrm{i}}=\mu_{\mathrm{i}} \quad\left(1-\mu_{\mathrm{i}}\right) /\left(\alpha_{\mathrm{i}}+\beta_{\mathrm{i}}+1\right)$. We incorporated parametric uncertainty in the replication loop by sampling $\mu_{\mathrm{i}}$ from a beta distribution, and $\sigma_{\mathrm{i}}$ from an inverse Gaussian distribution with mean $\mathrm{m}$ $(\mathrm{m}=0.001)$ and shape parameter $\lambda(\lambda=0.0001)$. We followed the same two-step approach for fertility seedbank or previous fall until spring, Bs plant survival and growth from spring to fall in the same year and Bu reproduction of small and large plants. Parameters are defined in Supplemental Materials, Table S3

parameters (FSM and FLG, fertility for small and large plants, respectively), but in this case fertility values were drawn from a Poisson distribution.

To account for density dependent effects, which result in decreased $T$. natans fertility and plant size (Groth et al. 1996), we modeled fertility values as a density-dependent parameter, such that number of seeds produced by small (FSM) or large (FLG) plants was dependent on the number of T. natans plants $(\mathrm{P})$ in the previous season (s)

$F_{s}=\frac{e^{\left(1-\left(z P_{s-1}\right)\right)}}{1+e^{\left(1-\left(z P_{s-1}\right)\right)}}$

we set $\mathrm{z}$, the regression parameter, to 0.0005 , indicating weak density-dependent effects. To model effects of management scenarios, we estimated average number of seeds produced by small or large plants (FSM or FLG, respectively) and weighted the value by rate of fertility decrease according to scenario. At each time step we estimated annual growth rate $(\lambda)$ as ratio between population size at current year $\left(\mathrm{N}_{\mathrm{t}+1}\right)$ and previous year $\left(\mathrm{N}_{\mathrm{t}}\right)$. Values of $\lambda>1$ indicate increasing populations while values of $\lambda<1$ indicate declining populations. We conducted all analysis using package popbio (Stubben and Milligan 2007) in R Core Team (2016). 
Results of demographic analyses

Plant area, seed output and germination varied significantly among populations and number of seeds per plant was positively correlated with plant area (Supplementary Materials, Fig. S1; Tables S1, S2). Asymptotic population growth rates varied significantly across populations (Supplementary Materials, Section 3). Elasticity analyses indicated that matrix elements representing germination of new seed and growth into large plants had the greatest influence on $\lambda$ (Supplementary Materials, Fig. S3).

\section{Results from modelled simulations}

Our model predicted that $T$. natans populations will continue to grow until carrying capacity or habitat requirements do not allow further expansion, despite continued attack by G. nymphaeae (Fig. 3). This indicates that if $T$. natans were a non-target species, $G$. nymphaeae would not constitute a demographic threat to $T$. natans populations despite regular feeding, oviposition and larval development. In contrast, our model predicts that $T$. natans populations will be greatly reduced when attacked by G. birmanica. After ten years simulated populations increased from 1000 plants to $>40,000$ plants when attacked by $G$. nymphaeae, but declined to near zero individuals under G. birmanica attack (Fig. 3). Thus, under our

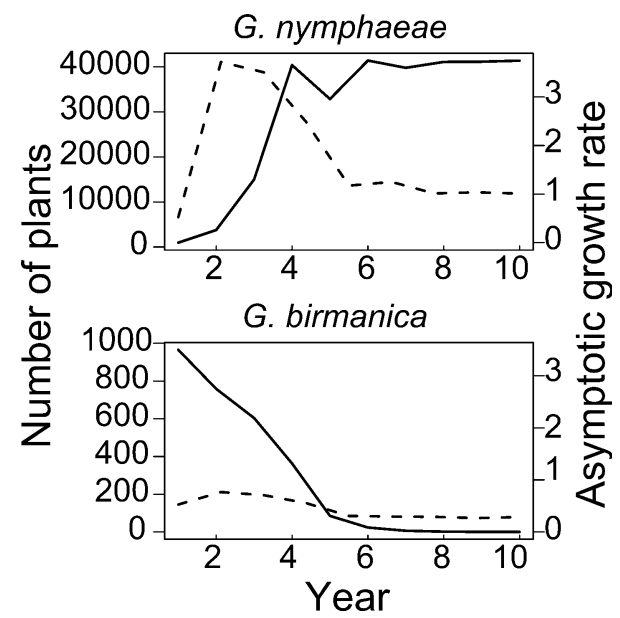

Fig. 3 Simulated population size (continuous line) and population growth rate (dashed line) of a T. natans population under attack by either the leaf beetle G. nymphaeae or G. birmanica. Model data are integrated means derived by collecting demographic data for four different $T$. natans populations hypothetical scenario of $T$. natans as a potential nontarget, $G$. birmanica would be a grave threat to continued existence of the species. If the goal were to safeguard T. natans, our results show that of these two extremely similar herbivores, G. nymphaeae would be a safe biocontrol agent while releases of $G$. birmanica should not be considered.

Implications for demographic assessments of nontarget effects

We considered a hypothetical example of $T$. natans as a non-target plant and evaluated potential threats by two herbivores that can successfully feed, oviposit and develop on the species. Under current decision making processes, biocontrol scientists or regulators would not consider $G$. nymphaeae a safe biocontrol agent because fundamental and field host range include $T$. natans. Field evidence from $>100$ years of association with T. natans in North America, and results from our demographic modeling efforts, however, clearly indicate that G. nymphaeae is no demographic threat to T. natans. Furthermore, there is no evolutionary tendency, despite enormous opportunity, to improve larval performance on the novel host, and female choice retains its preference for oviposition on the original host, even when larvae developed on $T$. natans (Ding and Blossey 2009). The traditional risk assessment process, as currently being implemented, would eliminate a potentially important biocontrol agent due to safety concerns regarding attack on $T$. natans, but this would be fundamentally unjustified given the realized demographic impact of G. nymphaeae. Our demographic assessments correctly predict what is evident in the field: G. nymphaeae does not affect $T$. natans populations, while G. birmanica attack can lead to rapid and severe population growth rate declines.

\section{Discussion}

Reports of non-target attack by weed biocontrol agents after their release has a chilling effect on agent approvals in ongoing programs, funding and recruitment (Moran and Hoffmann 2015). Land managers, ecologists, conservationists and weed biocontrol scientists spent enormous amounts of time discussing implications, focusing on the two high profile cases of 
$R$. conicus and $C$. cactorum, while critics implied that non-target impacts are potentially widespread, but not recognized (Louda et al. 2003). Almost 20 years have passed since the initial publications and while we have been provided with some evidence for negative demographic consequences by $R$. conicus, the same cannot be said for C. cactorum. Importantly, there is not a single publication documenting negative population level impacts on any other non-target plant species by weed biocontrol agents. Observation of herbivorous biocontrol agents feeding on other plants are widespread, indicating that evidence of their nontarget feeding is being recognized, collected and reported, but their attack appears inconsequential at the population level.

Unless there are unrecognized, or unpublished data on more widespread negative demographic consequences by approved weed biocontrol agents, the feared threats to native plants currently do not appear to exist. This is entirely overlooked by regulators, conservationists and ecologists who may equate feeding on non-target plants with demographic threats. The reliance on data about fundamental host range tests has been called risk-averse, but it ignores the increasing realized impacts of invasive plants on native biota (Downey and Paterson 2016), and increasing herbicide use by land managers that result in widespread and documented detrimental long-term effects to species of conservation concern (Kettenring and Adams 2011). We emphasize that society and citizens are entitled to have questions regarding performance of invasive species management methods answered to make informed decisions about priorities, risk acceptance and funding (Blossey 2016a, b), but this requires appropriate assessments and interpretation, not fear mongering and it should apply to all management methods (Kerr et al. 2016; Pearson et al. 2016).

Use of herbivore impact studies and demographic models in the way we have described here would be an important tool to evaluate efficacy and safety of potential biocontrol agents, yet it is completely unutilized despite its promise (Blossey 2016b). Use of plant (and herbivore) demography would be an important advancement in improving scientific rigor and predictability of weed biocontrol programs, albeit we acknowledge it will not be an easy transition. For far too long, the focus has been narrowly on fundamental host ranges and not allowing any attack on native plants. Pivoting to new risk assessment procedures and lines of evidence will take some time but we argue it is essential and well justified.

We acknowledge that biological control, like every other management technique, is not risk free and that ecological surprises may occur. For example, it appears that identity of plant species attacked during outbreak or spillover events is unpredictable (Blossey et al. 2001). But these are temporary events with no demographic consequences for attacked plant species and do not constitute host shifts. Assessing potential non-target effects is the ethical thing to do, but without use of demographic information on targets and nontargets biocontrol scientists and practitioners are vulnerable to accusations of inappropriate conduct and may get blamed for population declines or extinctions, whether these accusations are true or not. We argue that we should acknowledge our responsibilities for safeguarding the continued existence of populations of native or non-target species, and that demographic approaches provide a powerful tool for evaluating ecological risk. To the best of our knowledge, with the exception of $R$. conicus or $C$. cactorum, there is no weed biocontrol agent that has negatively affected populations of non-target plants. Given that hundreds of control agents have been released over 100 years across the world, this track record is exemplary (Winston et al. 2014). But we also may miss out on very promising herbivores, because the current regulatory climate makes scientifically questionable and poorly justified decisions (Cristofaro et al. 2013; Fowler et al. 2012; Groenteman et al. 2011; Hinz et al. 2014).

Our proposal to utilize demographic approaches in forecasting agent efficacy, and potential impacts on non-target species, would go a long way in improving the standing of the discipline-one grounded in theory and applying modern tools-while retaining our exemplary track record in safeguarding native species. This does not make weed biocontrol inherently more risky. On the contrary, we would be able to focus on effective agents with a proven track record of impact on demography of invasive plants, and lack of demographic impact on non-targets. Delivering this information to society and decision makers and regulators will constitute part of the accountability we should require from all of those engaged in invasive species management and stewardship (Blossey 2016a, b; Hare and Blossey 2014). 
Acknowledgements We appreciate support and assistance we have received from those supplying rosettes from local populations. We appreciate help with field work and common garden by Audrey Bowe and Jennifer Price for help with model development. Comments by several anonymous reviewers provided important feedback that improved our manuscript.

Open Access This article is distributed under the terms of the Creative Commons Attribution 4.0 International License (http:// creativecommons.org/licenses/by/4.0/), which permits unrestricted use, distribution, and reproduction in any medium, provided you give appropriate credit to the original author(s) and the source, provide a link to the Creative Commons license, and indicate if changes were made.

Funding Funding for this work was provided by the New York State Department of Conservation.

\section{References}

Ancheta J, Heard SB (2011) Impacts of insect herbivores on rare plant populations. Biol Conserv 144:2395-2402

Andreas JE, Schwarzländer M, de Clerck-Floate R (2008) The occurrence and potential relevance of post-release, nontarget attack by Mogulones cruciger, a biocontrol agent for Cynoglossum officinale in Canada. Biol Control 46:304-311

Arnett AE, Louda SM (2002) Re-test of Rhinocyllus conicus host specificity, and the prediction of ecological risk in biological control. Biol Conserv 106:251-257

Bernays EA, Chapman RF (1994) Host-plant selection by phytophagous insects. Contemporary topics in entomology. Springer, New York

Bernays E, Graham M (1988) On the evolution of host specificity in phytophagous arthropods. Ecology 69:886-892

Blossey B (2016a) The future of biological control: a proposal for fundamental reform. In: van Driesche R, Simberloff D, Blossey B, Causton C, Hoddle M, Marks C, Heinz K, Wagner D, Wagner K (eds) Integrating biological control into conservation practice. Wiley, Chichester, UK, pp 314-328

Blossey B (2016b) Measuring and evaluating ecological outcomes of biological control introductions. In: van Driesche R, Simberloff D, Blossey B, Causton C, Hoddle M, Marks C, Heinz K, Wagner D, Wagner K (eds) Integrating biological control into conservation practice. Wiley, Chichester, UK, pp 161-188

Blossey B, Casagrande R, Tewksbury L, Landis DA, Wiedenmann RN, Ellis DR (2001) Nontarget feeding of leaf-beetles introduced to control purple loosestrife (Lythrum salicaria L.). Nat Areas J 21:368-377

Briese DT (2005) Translating host-specificity test results into the real world: the need to harmonize the yin and yang of current testing procedures. Biol Control 35:208-214

Buckley YM, Rees M, Paynter Q, Lonsdale M (2004) Modelling integrated weed management of an invasive shrub in tropical Australia. J Appl Ecol 41:547-560
Carvalheiro LG, Buckley YM, Ventim R, Fowler SV, Memmott J (2008) Apparent competition can compromise the safety of highly specific biocontrol agents. Ecol Lett 11:690-700

Caswell H (2000) Prospective and retrospective perturbation analyses: their roles in conservation biology. Ecology 81:619-627

Caswell H (2001) Matrix population models: construction, analysis, and interpretation. Sinauer Associates, Sunderland

Caswell H, Salguero-Gomez R (2013) Age, stage and senescence in plants. J Ecol 101:585-595

Caswell H, Neubert MG, Hunter CM (2011) Demography and dispersal: invasion speeds and sensitivity analysis in periodic and stochastic environments. Theor Ecol 4:407-421

Catton HA, Lalonde RG, De Clerck-Floate RA (2014) Differential host-finding abilities by a weed biocontrol insect create within-patch spatial refuges for nontarget plants. Environ Entomol 43:1333-1344

Catton HA, Lalonde RG, De Clerck-Floate RA (2015) Nontarget herbivory by a weed biocontrol insect is limited to spillover, reducing the chance of population-level impacts. Ecol Appl 25:517-530

Catton HA, Lalonde RG, Buckley YM, De Clerck-Floate RA (2016) Biocontrol insect impacts population growth of its target plant species but not an incidentally used nontarget. Ecosphere 7:e01280. https://doi.org/10.1002/ecs2.1280

Clement SL, Cristofaro M (1995) Open field tests in hostspecificity determination of insects for biological control of weeds. Biocontrol Sci Technol 5:395-406

Clewley GD, Eschen R, Shaw RH, Wright DJ (2012) The effectiveness of classical biological control of invasive plants. J Appl Ecol 49:1287-1295

Crawley MJ (1989) The successes and failures of weed biocontrol using insects. Biocontrol News Inf 10:213-223

Cristofaro M, De Biase A, Smith L (2013) Field release of a prospective biological control agent of weeds, Ceratapion basicorne, to evaluate potential risk to a nontarget crop. Biol Control 64:305-314

Cronin G, Schlacher T, Lodge DM, Siska EL (1999) Intraspecific variation in feeding preference and performance of Galerucella nymphaeae (Chrysomelidae: Coleoptera) on aquatic macrophytes. J N Am Bent Soc 18:391-405

Davis AS, Landis DA, Nuzzo V, Blossey B, Gerber E, Hinz HL (2006) Demographic models inform selection of biocontrol agents for garlic mustard (Alliaria petiolata). Ecol Appl 16:2399-2410

De Clerck-Floate R, Schwarzländer M (2002) Host specificity of Mogulones cruciger (Coleoptera: Curculionidae), a biocontrol agent for houndstongue (Cynoglossum officinale), with emphasis on testing of native North American Boraginaceae. Biocontrol Sci Technol 12:293-306

DePrenger-Levin ME, Grant TA, Dawson C (2010) Impacts of the introduced biocontrol agent, Rhinocyllus conicus (Coleoptera: Curculionidae), on the seed production and population dynamics of Cirsium ownbeyi (Asteraceae), a rare, native thistle. Biol Control 55:79-84

DeWalt SJ (2006) Population dynamics and potential for biological control of an exotic invasive shrub in Hawaiian rainforests. Biol Invasion 8:1145-1158 
Ding J, Blossey B (2005) Impact of the native water lily leaf beetle, Galerucella nymphaeae (Coleoptera: Chrysomelidae), attacking introduced water chestnut, Trapa natans, in the northeastern United States. Environ Entomol 34:683-689

Ding J, Blossey B (2009) Difference in preference and performance of the water lily leaf beetle, Galerucella nymhaeae populations on native and invasive aquatic plants. Environ Entomol 38:1653-1660

Ding J, Blossey B, Du Y, Zheng F (2006a) Galerucella birmanica (Coleoptera: Chrysomelidae), a promising potential biological control agent of water chestnut, Trapa natans. Biol Control 36:80-90

Ding J, Blossey B, Du Y, Zheng F (2006b) Impact of Galerucella birmanica (Coleoptera: Chrysomelidae) on growth and seed production of Trapa natans. Biol Control 37:338-345

Downey PO, Paterson ID (2016) Encompassing the relative non-target risks from agents and their alien plant targets in biological control assessments. BioControl 61:615-630

Eckberg JO, Tenhumberg B, Louda SM (2014) Native insect herbivory limits population growth rate of a non-native thistle. Oecologia 175:129-138

Fowler SV, Syrett P, Hill RL (2000) Success and safety in the biological control of environmental weeds in New Zealand. Aust Ecol 25:553-562

Fowler SV, Paynter Q, Dodd S, Groenteman R (2012) How can ecologists help practitioners minimize non-target effects in weed biocontrol? J Appl Ecol 49:307-310

Futuyma DJ, Agrawal AA (2009) Macroevolution and the biological diversity of plants and herbivores. Proc Nat Acad Sci USA 106:18054-18061

Groenteman R, Fowler SV, Sullivan JJ (2011) St. John's wort beetles would not have been introduced to New Zealand now: a retrospective host range test of New Zealand's most successful weed biocontrol agents. Biol Control 57:50-58

Groth AT, LovettDoust L, LovettDoust J (1996) Population density and module demography in Trapa natans (Trapaceae), an annual, clonal aquatic macrophyte. Am J Bot 83:1406-1415

Guretzky JA, Louda SM (1997) Evidence for natural biological control: insects decrease survival and growth of a native thistle. Ecol Appl 7:1330-1340

Hare D, Blossey B (2014) Principles of public trust thinking. Hum Dimens Wildl 19:397-406

Hinz HL, Schwarzländer M, Gassmann A, Bourchier RS (2014) Successes we may not have had: a retrospective analysis of selected weed biological control agents in the United States. Invasive Plant Sci Manag 7:565-579

Jezorek H, Baker AJ, Stiling P (2012) Effects of Cactoblastis cactorum on the survival and growth of North American Opuntia. Biol Invasion 14:2355-2367

Johnson DM, Stiling PD (1996) Host specificity of Cactoblastis cactorum (Lepidoptera: Pyralidae), an exotic Opuntiafeeding moth, in Florida. Environ Entomol 25:743-748

Kerr NZ, Baxter PWJ, Salguero-Gomez R, Wardle GM, Buckley YM (2016) Prioritizing management actions for invasive populations using cost, efficacy, demography and expert opinion for 14 plant species world-wide. J Appl Ecol 53:305-316
Kettenring KM, Adams CR (2011) Lessons learned from invasive plant control experiments: a systematic review and meta-analysis. J Appl Ecol 48:970-979

Kunii H (1988) Longevity and germinability of buried seed in Trapa sp. Mem Fac Sci Shimane Univ 22:83-91

Louda SM, Kendall D, Connor J, Simberloff D (1997) Ecological effects of an insect introduced for the biological control of weeds. Science 277:1088-1090

Louda SM, Pemberton RW, Johnson MT, Follett PA (2003) Nontarget effects - the Achilles' heel of biological control: retrospective analyses to reduce risk associated with biocontrol introductions. Annu Rev Entomol 48:365-396

Louda SM, Rand TA, Arnett AE, McClay AS, Shea K, McEachern AK (2005a) Evaluation of ecological risk to populations of a threatened plant from an invasive biocontrol insect. Ecol Appl 15:234-249

Louda SM, Rand TA, Russell FL, Arnett AE (2005b) Assessment of ecological risks in weed biocontrol: input from retrospective ecological analyses. Biol Control 35:253-264

Marohasy J (1996) Host shifts in biological weed control: real problems, semantic difficulties or poor science? Int J Pest Manag 42:71-75

McEvoy PB, Coombs EM (1999) Biological control of plant invaders: regional patterns, field experiments, and structured population models. Ecol Appl 9:387-401

McEvoy PB, Higgs KM, Coombs EM, Karacetin E, Starcevich LA (2012) Evolving while invading: rapid adaptive evolution in juvenile development time for a biological control organism colonizing a high-elevation environment. Evol Appl 5:524-536

McFadyen REC (1998) Biological control of weeds. Annu Rev Entomol 43:369-393

McGowan CP, Runge MC, Larson MA (2011) Incorporating parametric uncertainty into population viability analysis models. Biol Conserv 144:1400-1408

Moran VC, Hoffmann JH (2015) The fourteen international symposia on biological control of weeds, 1969-2014: delegates, demographics and inferences from the debate on non-target effects. Biol Control 87:23-31

Moran VC, Hoffmann JH, Zimmermann HG (2005) Biological control of invasive alien plants in South Africa: necessity, circumspection, and success. Front Ecol Environ 3:77-83

Paynter QE, Fowler SV, Gourlay AH, Haines ML, Harman HM, Hona SR, Peterson PG, Smith LA, Wilson-Davey JA, Winks CJ, Withers TM (2004) Safety in New Zealand weed biocontrol: a nationwide survey for impacts on nontarget plants. N Z Plant Prot 57:102-107

Paynter Q, Martin N, Berry J, Hona S, Peterson P, Gourlay AH, Wilson-Davey J, Smith L, Winks C, Fowler SV (2008) Non-target impacts of Phytomyza vitalbae a biological control agent of the European weed Clematis vitalba in New Zealand. Biol Control 44:248-258

Paynter Q, Fowler SV, Gourlay AH, Peterson PG, Smith LA, Winks CJ (2015) Relative performance on test and target plants in laboratory tests predicts the risk of non-target attack in the field for arthropod weed biocontrol agents. Biol Control 80:133-142

Pearson DE, Ortega YK, Runyon JB, Butler JL (2016) Secondary invasion: the bane of weed management. Biol Conserv 197:8-17 
Pemberton RW (1995) Cactoblastis cactorum (Lepidoptera: Pyralidae) in the United States: an imigrant biological control agent or an introduction of the nursery industry? Am Entomol 41:230-232

Pemberton RW (2000) Predictable risk to native plants in weed biocontrol. Oecologia 125:489-494

Pemberton RW, Liu H (2007) Control and persistence of native Opuntia on Nevis and St. Kitts 50 years after the introduction of Cactoblastis cactorum. Biol Control 41:272-282

R Core Team (2016) R: a language and environment for statistical computing. R Foundation for Statistical Computing, Vienna, Austria. http://www.r-project.org/

Raghu S, Wilson JR, Dhileepan K (2006) Refining the process of agent selection through understanding plant demography and plant response to herbivory. Aust $\mathrm{J}$ Entomol 45:308-316

Rand TA, Louda SM (2004) Exotic weed invasion increases the susceptibility of native plants attack by a biocontrol herbivore. Ecology 85:1548-1554

Rose KE, Louda SM, Rees M (2005) Demographic and evolutionary impacts of native and invasive insect herbivores on Cirsium canescens. Ecology 86:453-465

Salguero-Gomez R, Jones OR, Archer CR, Buckley YM, CheCastaldo J, Caswell H, Hodgson D, Scheuerlein A, Conde DA, Brinks E, de Buhr H, Farack C, Gottschalk F, Hartmann A, Henning A, Hoppe G, Roemer G, Runge J, Ruoff T, Wille J, Zeh S, Davison R, Vieregg D, Baudisch A, Altwegg R, Colchero F, Dong M, de Kroon H, Lebreton JD, Metcalf CJE, Neel MM, Parker IM, Takada T, Valverde T, Velez-Espino LA, Wardle GM, Franco M, Vaupel JW (2015) The COMPADRE plant matrix database: an open online repository for plant demography. J Ecol 103:202-218

Sauby KE, Kilmer J, Christman MC, Holt RD, Marsico TD (2017) The influence of herbivory and weather on the vital rates of two closely related cactus species. Ecol Evol 7:6996-7009

Shea K, Kelly D (1998) Estimating biocontrol agent impact with matrix models: Carduus nutans in New Zealand. Ecol Appl 8:824-832

Shea K, Kelly D, Sheppard AW, Woodburn TL (2005) Contextdependent biological control of an invasive thistle. Ecology 86:3174-3181

Sheppard AW, Warner KD (2016) Societal values expressed through policy and regulation concerning biological control releases. In: van Driesche R, Simberloff D, Blossey B, Causton C, Hoddle M, Marks C, Heinz K, Wagner D, Wagner K (eds) Integrating biological control into conservation practice. Wiley, Chichester, pp 247-263

Sheppard AW, van Klinken RD, Heard TA (2005) Scientific advances in the analysis of direct risks of weed biological control agents to nontarget plants. Biol Control $35: 215-226$
Simberloff D, Stiling P (1996) How risky is biological control? Ecology 77:1965-1974

Smilanich AM, Fincher RM, Dyer LA (2016) Does plant apparency matter? Thirty years of data provide limited support but reveal clear patterns of the effects of plant chemistry on herbivores. New Phytol 210:1044-1057

Smith M, Caswell H, Mettler-Cherry P (2005) Stochastic flood and precipitation regimes and the population dynamics of a threatened floodplain plant. Ecol Appl 15:1036-1052

Stiling P, Rossi A, Gordon D (2000) The difficulties of single factor thinking in restoration: replanting a rare cactus in the Florida Keys. Biol Conserv 94:327-333

Stubben CJ, Milligan BG (2007) Estimating and analyzing demographic models using the popbio package in R. J Stat Softw 22:1-23

Suckling DM, Sforza RFH (2014) What magnitude are observed non-target impacts from weed biocontrol? PLoS ONE 9(1):e84847. https://doi.org/10.1371/journal.pone. 0084847

Swope SM, Satterthwaite WH, Parker IM (2017) Spatiotemporal variation in the strength of density dependence: implications for biocontrol of Centaurea solstitialis. Biol Inv 19:2675-2691

Takahashi M, Louda SM, Miller TEX, O'Brien CW (2009) Occurrence of Trichosirocalus horridus (Coleoptera: Curculionidae) on native Cirsium altissimum versus exotic C. vulgare in North American tallgrass prairie. Environ Entomol 38:731-740

USDA (2016) Technical advisory group for biological control agents of weeds manual, Interim edn. United States Department of Agriculture, Washington, DC, USA

van Klinken RD, Edwards OR (2002) Is host specificity of weed biocontrol agents likely to evolve rapidly following establishment? Ecol Lett 5:590-595

Vigueras AL, Portillo L (2001) Uses of Opuntia species and the potential impact of Cactoblastis cactorum (Lepidoptera: Pyralidae) in Mexico. Fla Entomol 84:493-498

Wapshere AJ (1974) A strategy for evaluating the safety of organisms for biological weed control. Ann Appl Biol 77:200-211

Williams BK, Nichols JD, Conroy MJ (2001) Analyses and management of animal populations. Academic Press, New York

Winkler I, Mitter C (2008) The phylogenetic dimension of insect/plant interactions: a summary of recent evidence. In: Tilmon K (ed) Specialization, speciation, and radiation: the evolutionary biology of herbivorous insects. University of California Press, Berkeley, pp 240-263

Winston RL, Schwarzländer M, Hinz HL, Day MD, Cock MJW, Julien MH (eds) (2014) Biological control of weeds: a world catalogue of agents and their target weeds, 5th ed. USDA Forest Service, Forest health technology enterprise team, Morgantown, West Virginia, USA. FHTET-2014-04 